\title{
Article
}

\section{Recent developments for naturalizing the mind.}

Thornton, Tim

Available at http://clok.uclan.ac.uk/3211/

Thornton, Tim ORCID: 0000-0002-0137-1554 (2011) Recent developments for naturalizing the mind. Current opinion in psychiatry, 24 (6). pp. 502-6. ISSN $1473-6578$

It is advisable to refer to the publisher's version if you intend to cite from the work. http://dx.doi.org/10.1097/YCO.0b013e32834b7b24

For more information about UCLan's research in this area go to http://www.uclan.ac.uk/researchgroups/ and search for < name of research Group>.

For information about Research generally at UCLan please go to http://www.uclan.ac.uk/research/

All outputs in CLoK are protected by Intellectual Property Rights law, including Copyright law. Copyright, IPR and Moral Rights for the works on this site are retained by the individual authors and/or other copyright owners. Terms and conditions for use of this material are defined in the policies page.

\section{CLoK}

Central Lancashire online Knowledge www.clok.uclan.ac.uk

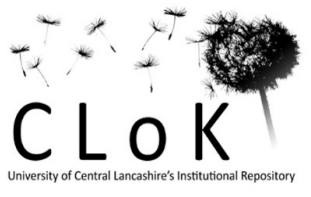


Full Title: $\quad$ Recent developments for naturalising the mind

Short title: Recent developments for naturalising the mind

Authors (i.e. name as it should appear on the paper):

Tim Thornton

Position (i.e. job description as it should appear on the paper):

Professor of Philosophy and Mental Health

\section{Address for correspondence:}

School of Health

University of Central Lancashire

Preston

PR1 2HE

Other Contact Details:

Phone: 07811286099

Fax: (do not have one)

Email: TThornton1@uclan.ac.uk

Key-words (not appearing in title):

reductionism; representation; teleosemantics; interpretivism; rationality

Word count (excluding title page but including references):

$\sim 3,000$

Character count (abstract):

Software used: Microsoft Word

Filename(s): 


\title{
Recent developments for naturalising the mind
}

\author{
Abstract \\ Purpose of review: to examine recent philosophical work which impacts on fitting mental content \\ into a satisfactory picture of nature.
}

Recent findings: both reductionist and non-reductionist forms of naturalism about mental content have sustained criticism.

Summary: The connection between having a mind and fitting a rational pattern remains an important insight.

Key words: reductionism; representation; teleosemantics; interpretivism; rationality.

\section{Introduction}

The philosophy of mind and psychiatry seem to be complementary disciplines investigating the same central issues. What is the nature of the mind, of the brain and body, and of their relation? Much of the work of both disciplines is concerned with those central issues.

Over the last fifty years, philosophy has evolved a number of broad theories of the nature of the connection. They have ranged from the Churchlands' eliminativist denial that there are mental states in favour merely of brain states [1], through forms of type-type reductionism such as typetype identity physicalism, which identifies types of mental state with types of physical state; behaviourism, which identifies types of mental state with types of behavioural state and functionalism, which identifies types of mental state with types of second order functional state [2]. These last three approaches all aim to shed light on the mental in other terms (physical, behavioural and functional). They all face the challenge of avoiding, in Ned Block's terms, chauvinism and liberalism: ruling out possible minds or counting as minds systems which intuitively are not [3].

More modestly, Donald Davidson's anomalous monism identifies each token mental event with a physical event (they are one and the same event) [4]. But what unites different mental tokens as instances of the same mental type (the same kind of belief or sensation) is not explained in, or reduced to, physical terms but rather by fitting them into a rational pattern of behaviour. It is a pattern that makes sense by contrast with being merely statistically usual and thus, Davidson argues, it has 'no echo in physical theory'. Finally, there are positions which attempt no such reduction of the mental to the physical often emphasising the irreducibility of the qualitative aspects of mental lives - their qualia - or their intentionality or mental content.

One position in this debate which, whilst still not mainstream within straight philosophy of mind, has enjoyed popularity within the philosophy of psychiatry is enactivism, discussed in two recent summaries [5, 6]. Its starting assumption is to stress the embodied, extended, embedded and enactive nature of the human mind and to use bodily interactions with the natural environment to account for features of the mind, including both intentionality and qualitative aspects of experience. It contrasts with the still dominant orthodoxy of representationalist theories of mind which postulate mental representations characterised in information processing terms to carry (as 'vehicles') or encode mental content running on the brain as a kind of computer. Although varying in its explanatory aims, enactivist approaches share the assumption that the mind is extended beyond the boundaries of the skull. Having mental states depends on one's body not just one's brain. Nor are such mental states just caused by states of the body (since even those who think that the mind is software running on the brain can hold that) but rather constituted in a particular way by them.

This last qualification ('particular') is related to a way in which enactivism cannot be easily be mapped onto the debate discussed in the rest of this review. It concerns not just the extra-cranial constitution of mental content - the content of thoughts, for example - but rather the extra-cranial mechanisms that carry or encode that content. An analogy: the marks that make up this sentence are the vehicles that carry, or encode, its meaning, which is itself partly constituted by broader social 
facts about written language, external to just this sentence. Conventional externalists think that the contents of some thoughts are also fixed by factors external to their thinkers: such as the linguistic community or the physical environment. Enactivism is both less and more radically externalist. Less, in that the focus is on the extra-cranial body not the broader environment. More, because it concerns the bodily vehicles of thought not just the contents carried by those vehicles.

I suspect that the popularity of enactivism in the philosophy of psychiatry is that it promises a translation between traditions. There has been continuity within European psychiatry between descriptive psychopathology and the philosophical tradition of phenomenology, exemplified in the work of Merleau Ponty, by a stress on embodiment. Work by Stanghellini $\left[7,8^{* *}, 9^{* *}\right]$ and Fuchs $\left[10^{* *}\right]$ are examples of this philosophically and phenomenologically informed approach to understanding psychopathology. In the UK and USA books and papers by Ratcliffe [11**, 12*] and Gallagher $\left[13,14^{*}\right]$ also draw on phenomenology whilst also engaging with Anglo-American analytic philosophy. Since enactivism shares with recent phenomenology assumptions about the role of the body but has been developed to address the agenda in Anglo-American analytic philosophy of mind, it promises to be a bridge between that and the problems of understanding psychopathology.

If the problem of understanding the relation between mind and body is made more difficult by the challenge of either accounting for (or somehow dismissing) the qualitative aspects of experience and its intentionality, recent developments have challenged some assumptions about these aspects. In this review, I will focus on intentionality, starting first with accounts which attempt to locate mental states in nature by reducing them and then mentioning an alternative non-reductionist form of naturalism.

\section{Representationalism}

The orthodox approach to shedding light on the intentionality of mental states is representationalism of which Jerry Fodor's early work was a very clear statement [15]. He combined the idea that the systematicity and compositionality of thought is explained by structured mental representations or symbols in a language of thought with a variant of a causal theory of how the symbols come to have worldly content or reference: the asymmetric dependence theory which is designed to explain how false thought or misrepresentation is so much as possible.

Fodor's recent book, LOT 2: The Language of Thought Revisited, restates and develops this picture taking what he calls 'pragmatism' as the key target, the idea that thought's key role is action rather than representation 'So, one of the ways in which LOT 2 differs from LOT 1 is in the singlemindedness with which it identifies pragmatism as the enemy par excellence of Cartesian realism about mental states' [16**].

An alternative form of representationalism - teleosemantics - accounts for the possibility of falsity not merely through a complex causal mechanism, or what typically causes a representation, but through the idea of biological or proper function and thus what the representation is biologically designed to represent. The proper function of a biological trait is what it is designed, or ought, to do, explained in evolutionary terms as that feature which best its explains its selective advantage and thus continued presence in the population. The proper function of a putative mental representation of a biological system is what it is designed to represent, picked out as what best explains the mental representation's selective advantage and thus continued presence in the population.

Teleosemantics came to prominence through the work of Millikan who distinguishes between biological mechanisms which 'produce' representations, such as perceptual systems, and mechanisms which 'consume' them [17]. These might include mechanisms designed for predator evasion. It is the contribution that the representation makes to the consumer mechanism that determines its content: such as representing the presence of a predator. 
This is an ongoing research programme [18]. But it has recently received a substantial and sustained criticism which threatens to undermine the key idea of mental representations deployed to explain the everyday intentionality of mental states.

\section{Challenges to representationalism}

In a summary of attempts to naturalise content through the idea of biological representations, Peter Godfrey-Smith expresses pessimism. 'I doubt that teleosemantics, or any theory like it, will deliver the direct, reductive, puff-of-papal smoke solution that the 1980s literature envisaged' [19]. His reason is that 30 years of philosophical theorising has delivered something in the same area but more basic.

One of the intuitions that has driven teleosemantics is the idea that rich biological concepts of function pick out a special kind of involvement relation between parts of organisms and their environments. Edging even closer to the semantic domain, there is a kind of specificity or directness that an evolved structure can have towards an environmental feature that figures in its selective history... But this relation is found in many cases that do not involve representation or anything close to it. [19]

A more general critique of reductionist accounts of mental content is provided by William Ramsey in his book Representation Reconsidered [20**]. Ramsey points out that a lesson from the history of the philosophy of mind is that, as Dan Dennett noted, it is nearly always possible to describe physical processes in representational terms but it is never necessary. Just as one can avoid biological descriptions by describing biological systems in lower level physical and chemical terms, so representational terms need not be used. What then justifies the use of representational terms for complex systems? What is the explanatory benefit? Ramsey calls this the 'job description challenge'. He argues that all the dominant approaches to explaining intentionality fail this test.

Take the case of a Venus fly trap which, according to Fred Dretske's teleosemantic analysis, is supposed to have an internal trigger which responds to movement and thus signals the presence of insects [21]. Drekske says 'there is every reason to think that this internal trigger was selected for its job because of what it indicated, because it told the plant what it needed to know'. But Ramsey asks why we need think of this in representational terms in addition to thinking that, because of the lawlike connection between movement and plant closure, plants with the trigger would be selected. ' $[T]$ here is no reason to think that structures recruited because their states have the property of being nomically dependent on some condition are also recruited because they carry information about that condition' [20]. This mirrors the case of the firing pin in a gun which bridges the gap between pulling the trigger and firing the round. That lawlike connection is why the pin is part of the design. But there is no reason to think that the firing pin is a representation of anything.

Dan Hutto draws support from such criticisms of the attempt to locate representational content at sub-personal levels in his version of enactivism: 'radical enactivism' [22*]. Arguing that other forms, such as Alva Noë's, illicitly smuggle in sub-personal cognitive notions, his own builds in no assumption that content or meaning can play a role lower than the level of whole people [23]. Nevertheless, he still wishes to appeal to some notion of primitive normative directedness: a kind of 'teleosemiotics' which offers continuity between non-linguistic animals and humans. It remains a matter of debate, however, how exactly such an enactivist view helps to clarify intentional content at the level of whole people.

\section{Interpretivism}

Although reductionist naturalism is the dominant approach to meaning or content, there is another approach to locating meaning in nature, interpretivism, which combines two claims. First there are distinct and somewhat independent levels of description of mental and physical states. Thus, following Jaspers, whilst brain events are susceptible to scientific and lawlike explanation, mental events including the speech, action and experiences of whole people, are subject to understanding. 
Second, understanding essentially involves fitting mental states into rational patterns. Having a mind implies that one's speech and action is interpretable and that to be interpretable requires that one is largely rational. One issue, especially for psychiatry, is to fathom how these very different levels connect: the interface problem [24, 25].

\section{Challenges to interpretivism}

The idea of independent levels of description has come under scrutiny in the philosophy of psychiatry, recently. Dominic Murphy, for example, has attempted to show how Marr's threefold distinction between levels - computational theory, representation and algorithm, hardware implementation [26] - can be applied to psychiatric explanation. Murphy points out that Marr thinks of the levels in epistemic terms: as different ways of understanding the same system. One can determine its goals, the algorithm by which it determines those goals or the physical set up which implements that algorithm.

For example, Frith's account of passivity phenomena and thought insertion is based on the breakdown of a mechanism described at the computational level: 'intentions are monitored in order to distinguish between actions caused by our own goals and plans (willed actions) and actions that are in response to external events (stimulus-driven actions). Such monitoring is essential if we are to have awareness of the causes of our actions... A failure to monitor intentions to act would result in delusions of control and other passivity experiences' [27]. The next level down - representation and algorithm - would detail how Frith's postulated efference copy represents intentions and how it is compared to representations of changes of experience in a monitoring system. The implementation level concerns the neurology which carries or encodes these higher level processes: perhaps a system of dopamine neurons.

But, Murphy argues, one might think of these different levels as describing not different ways of understanding the same system but distinct forms of organisation in nature or distinct causal structures pitched at different ontological levels: 'higher levels are made up of lower level things, and at each level things interact with each other rather than with things at lower levels' [28**].

In psychiatry, however, neither of these pictures is quite right, according to Murphy, because there are different systems operating at different levels, unlike the epistemic view, but the different levels interact, unlike the latter view. Thus whilst Marr's description of levels suggest that they are partly independent (the computational level constrains but does not determine the causal mechanisms that implements it), Murphy suggests that in psychiatry causes described at one level will have effects at another so that useful generalisations will cross levels.

John Campbell is more radical and argues that the very idea multi-level model of explanation in psychiatry results from a pre-Humean assumption about the intelligibility of relations tracked in causal explanation [29, 30**]. He criticises Christopher Frith's assumptions about the explanation of thought insertion. Frith claims that whether or not there are inappropriate firings of dopamine neurons, that fact cannot be used to explain thought insertion as it sheds no light on why just that kind of symptom was produced. Frith assumes we need an account pitched at a particular level: that of a sub-personal but still cognitive model of mechanisms.

Campbell suggests that the assumption that there is a right level of explanation which clarifies things in the way Frith desires is the result of a pre-Humean view of causal explanation. Resisting the idea that the right kind of cause and effect have to be intelligibly, rather than merely brutely, related undercuts the motivation for the levels of explanation picture.

Just as we find it natural to expect there to be an intelligible mechanism underpinning material causal connections - even if this assumption lacks any genuine a priori justification - so Campbell also suggests that in the case of mental causation we expect there to be a rational connection between propositional attitudes. (The desire for nourishment combined with the belief that bread nourishes rationalises and thus causes a desire for bread.) The rational link between propositional 
attitudes is our paradigm of a mental causal mechanism. Again, however, whilst that idea is natural, it lacks a priori justification and should be resisted.

Weakening the requirement on rationality also promises to ease the problem of accounting for delusions. If rationality is a precondition for interpretability, what are we to make of the apparently mental but apparently non-rational psychopathological experiences and states?

In her recent book Delusions and Other Irrational Beliefs, Lisa Bortolotti draws a key distinction between 'conformity with' and 'subscription to' norms of rationality [31**]. The former implies actual successful agreement with rational norms whilst the latter is merely an aim to follow them. If we assume that interpretability is tied to the first then there are problems with real cases of inconsistency. If we think merely that interpreting people requires merely taking them to subscribe to norms of rationality, we can defend actual inconsistency but then, if subscription doesn't imply general conformity, it is no help in singling out an interpretation of behaviour and thus ascribing mental states. So Bortolotti concludes that, if there is no connection between subscription and conformity, then the link between rationality and the ascription of mentality is lost. Further, drawing on empirical work on the reasoning of those not suffering from delusional states, Bortolotti argues that this is entirely plausible.

The question both Campbell's and Bortolotti's criticisms of the role of rationality for the ascription of mentality raises, however, is how light is shed on the mental in general without it. Placing utterances, actions and other states and experiences in a rational pattern seems to be the only way to understand what it is about them that counts as expressive of minds [32].

Indeed, an extreme example of this wide view is Michael Thompson's influential Life and Action which connects philosophy of mind exemplified in debate about what makes something an action with broader concepts of morally charged social practices and the nature of life itself [33**]. In complete contrast to a reductionist focus on the micro-structure of our minds, Thompson looks to the broader context in which we live our life, act and pursue morally charged practices. But this leaves the challenge of how this broader canvas can be related back to the neurological data produced by psychiatry. The question of relating the broader and narrower pictures of human subjectivity remains pressing.

\section{Conclusion}

Both reductionist and non-reductionist forms of naturalism about mental content have come under recent fire. But the most promising approach to understanding the place of meaning in nature still seems to have to connect it to broader rational patterns of experience, speech and action.

- There are two main research programmes for explaining how mental content fits into nature: reductionist accounts of representation and non-reductionist interpretivism.

- The assumption that representation can be reduced to lower level explanation is increasingly under threat.

- Criticisms of the role of rationality in non-reductionist naturalism threatens to make the ascription of mentality mysterious.

\section{Acknowledgements}

None

\section{References}

1: Churchland, P. (1989) A Neurocomputational Perspective: the nature of mind and the structure of science, Cambridge, Mass.: MIT Press.

2: Fulford, K.W.M., Thornton, T. and Graham, G. (2006) Oxford Textbook of Philosophy and Psychiatry, Oxford: Oxford University Press 
3: Block, N. (1980) 'Troubles with functionalism' in Block, N. (ed) Readings in Philosophy of Psychology, London: Methuen.

4: Davidson, D. (1980) Essays on Actions and Events, Oxford: Oxford University Press.

5: Drayson, Z. (2009) 'Embodied Cognitive Science and Its Implications for Psychopathology' Philosophy, Psychiatry and Psychology 16: 329-40

6: Potter, N. (2010) 'Recent developments in philosophy of mind and psychopathology' Current Opinion in Psychiatry 23: 542-545

7: Stanghellini, G. (2004) Disembodied Spirits and Deanimated Bodies, Oxford: Oxford University Press

8: ** Stanghellinia, G. and Ballerini, M. (2011) 'What Is It like to Be a Person with Schizophrenia in the Social World? A First-Person Perspective Study on Schizophrenic Dissociality - Part 1: State of the Art' Psychopathology 2011;44:172-182 One of a pair of papers which together first make a case for combining phenomenological insights and empirical work to understanding the experiences of schizophrenia.

9: ** Stanghellinia, G. and Ballerini, M. (2011) 'What Is It like to Be a Person with Schizophrenia in the Social World? A First-Person Perspective Study on Schizophrenic Dissociality - Part 2:

Methodological Issues and Empirical Findings' Psychopathology 2011;44:183-192 One of a pair of papers which together first make a case for combining phenomenological insights and empirical work to understanding the experiences of schizophrenia.

10: ** Fuchs, T. (2009) 'Embodied cognitive neuroscience and its consequences for psychiatry' Poiesis and Praxis 6:219-233 A clear example of the combination of a phenomenological framework with empirical data.

11: **Ratcliffe, M. (2008) Feelings of Being: Phenomenology, Psychiatry and the Sense of Reality, Oxford: Oxford University Press. A book length treatment of delusion from a phenomenological tradition.

12 * Ratcliffe, M. (2009) 'Understanding existential changes in psychiatric illness: the indispensability of phenomenology' in Bortolotti, L. and Broome, M. Psychiatry as Cognitive Neuroscience, Oxford: Oxford University Press: 223-244. An argument for the role of phenomenology alongside empirical analysis.

13: Gallagher, S. (2005). How the Body Shapes the Mind, New York: Oxford University Press

14: *Gallagher, S. (2009) 'Delusional realities' in Bortolotti, L. and Broome, M. Psychiatry as Cognitive Neuroscience, Oxford: Oxford University Press: 245-266 An investigation of delusion exemplifying Gallagher's interdisciplinary account of mind.

15: Fodor, J. (1987) Psychosemantics: the problem of meaning in the philosophy of mind, Cambridge, Mass.: MIT Press.

16: ** Fodor, J. (2008) LOT 2: The Language of Thought Revisited, Oxford: Oxford University Press. A robust restatement of Fodor's representationalist and cognitivist theory of mind.

17: Millikan, R.G. (1984) Language, thought and other biological categories, Cambridge, Mass.: MIT Press

18: Macdonald, G. and Papineau, P. (eds) (2006) Teleosemantics, Oxford: Oxford University Press

19: Godfrey-Smith P. (2006) 'Mental Representation and Naturalism' in Macdonald, G. and Papineau, P. (eds) Teleosemantics, Oxford: Oxford University Press pp. 42-68

20: ** Ramsey, W.M. (2007) Representation Reconsidered, Cambridge: Cambridge University Press. A substantial critique of modern representationalism. 
21: Dretske, F. (1988) Explaining Behavior, Cambridge, Mass.: MIT Press

22: * Hutto, D. (2010) 'Radical Enactivism and Narrative Practice: Implications for Psychopathology' in Fuchs, T., Henningsen, P., Sattel, H. (eds) Coherence and Disorders of the Embodied Self, Stuggart: Schattauer pp43-66. An attempt to synthesise an enactivist view of the mind with recent empirical findings.

23: Noë A. (2004) Action in Perception. Cambridge, MA: MIT Press

24: Bermúdez, J.L. (2005) Philosophy of Psychology, London: Routledge

25: Thornton, T. (2009) 'On the interface problem in philosophy and psychiatry' in Bortolotti, L. and Broome, M. Psychiatry as Cognitive Neuroscience, Oxford: Oxford University Press: 121-136

26: Marr, D. (1982) Vision, San Francisco: W. H. Freeman

27: Frith, C (1992) The cognitive neuropsychology of schizophrenia Hove : Lawrence Erlbaum

28: ** Murphy, D. (2008) 'Levels of explanation in psychiatry' in Kendler, K. S. and Parnas, J. (eds)

Philosophical Issues in Psychiatry. Baltimore: Johns Hopkins University Press. A critique of a standard reading of Marr's view to better fit psychiatry.

29: Campbell, J. (2008) 'Causation in psychiatry' in Kendler, K. S. and Parnas, J. (eds) Philosophical Issues in Psychiatry. Baltimore: Johns Hopkins University Press

30: ** Campbell, J. (2009) 'What does rationality have to do with psychological causation? Propositional attitudes as mechanisms and as control variables' in Bortolotti, L. and Broome, M. (eds) Psychiatry as Cognitive Neuroscience. Oxford: Oxford University Press. A challenge to an intuitive view of the role of rationality in mental causation.

31: ** Bortolotti, L. (2010) Delusions and Other Irrational Beliefs, Oxford: Oxford University Press. A substantial discussion of the state of the art in the analysis of delusion.

32: Thornton, T. (2010) 'Psychiatric explanation and understanding' European Journal of Analytic Philosophy 6: 95-111

34: ** Thompson, M. (2008) Life and Action: Elementary structures of practice and practical thought, Cambridge, Mass.: Harvard University Press. A ground breaking book connecting a view of the person to broader themes of life-forms in general and moral practices. 